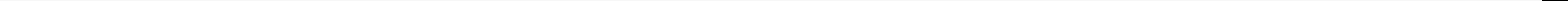




\section{DISCLAIMER}

Portions of this document may be illegible in electronic image products. Images are produced from the best available original document. 
GA-A22109

UC-420

\title{
FUSION TECHNOLOGY DEVELOPMENT
}

\author{
ANNUAL REPORT TO THE \\ U.S. DEPARTMENT OF ENERGY
}

OCTOBER 1, 1993 THROUGH SEPTEMBER 30, 1994

\author{
by
PROJECT STAFF
}

Work supported by

U.S. Department of Energy

under Contract No. DE-AC03-89ER52153 


\section{DISCLAIMER}

This report was prepared as an account of work sponsored by an agency of the United States Government. Neither the United States Government nor any agency thereof, nor any of their employees, makes any warranty, express or implied, or assumes any legal liability or responsibility for the accuracy, completeness, or usefulness of any information, apparatus, product, or process disclosed, or represents that its use would not infringe privately owned rights. Reference herein to any specific commercial product, process, or service by trade name, trademark, manufacturer, or otherwise, does not necessarily constitute or imply its endorsement, recommendation, or favoring by the United States Government or any agency thereof. The views and opinions of authors expressed herein do not necessarily state or reflect those of the United States Government or any agency thereof.

This report has been reproduced directly from the beat available copy

Available to DOE and DOE contractors from the

Office of Scientific and Tecturical Information

P.O. Box 62

Oak Ridge, TN 37831

Prices available from (615) 576-8401,

FTS 626-8401

Available to the public from the

National Tectnical Information Service

U.S. Department of Commerce

6285 Port Royal Road

Springfield, VA 22161 


\section{CONTENTS}

1. FUSION TECHNOLOGY DEVELOPMENT OVERVIEW .................................. 1

2. FUSION POWER PLANT DESIGN STUDIES ................................................. 3

2.1. Overview ................................................................................................ 3

2.2. Project Coordination .............................................................................. 3

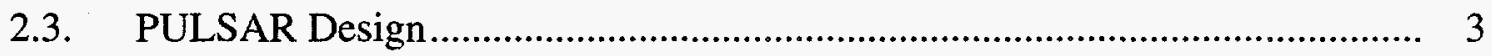

2.3.1. Introduction...................................................................... 3

2.3.2. Divertor Design ...................................................................... 4

2.4. Starlite/Demo Design Project .............................................................. 5

2.5. Project Planning ............................................................................. 5

2.6. Demo Design ............................................................................ 5

2.6.1. Work Breakdown Structure (WBS) ........................................... 5

2.6.2. Critical Design Issues .............................................................. 5

2.6.3. Safety and Licensing.............................................................. 5

2.6.4. Divertor Design ................................................................... 6

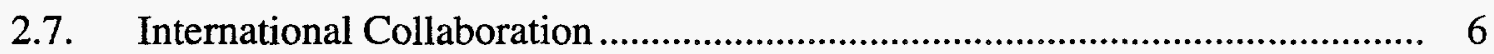

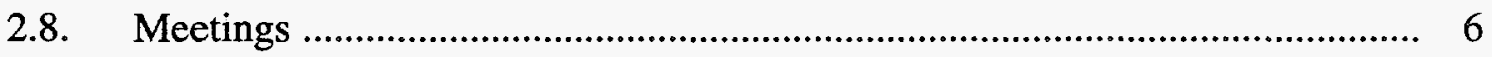

2.9. Publications.............................................................................. 6

3. PLASMA INTERACTIVE MATERIALS .................................................... 7

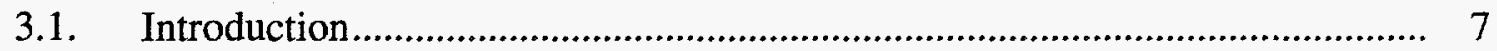

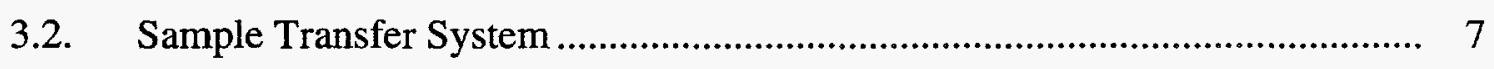

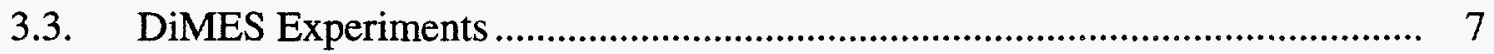

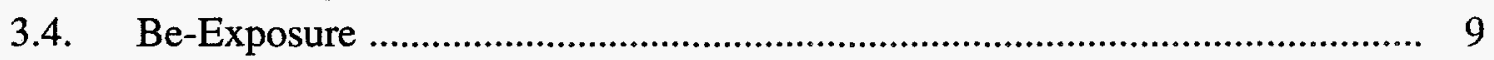

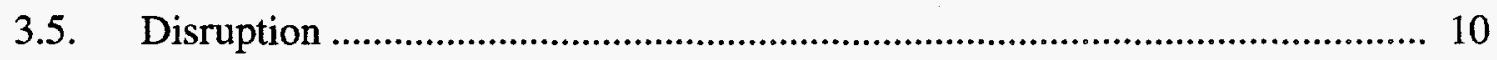

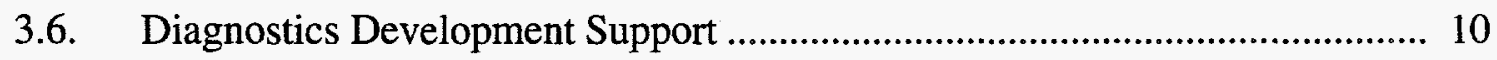

3.7. International Collaboration ................................................................. 10

3.7.1. Germany ......................................................................... 10

3.7.2. People's Republic of China ................................................... 11

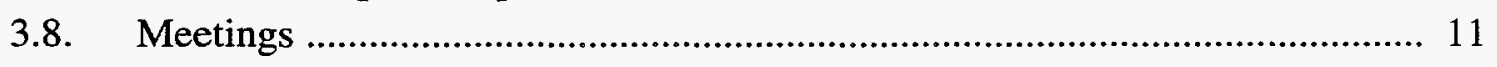

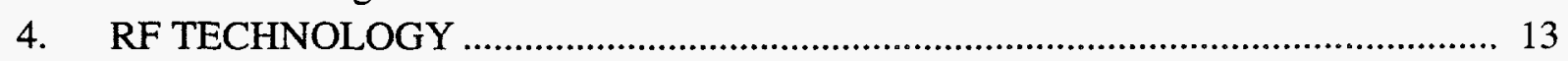

4.1. Coordination of International Activities .................................................. 13

4.2. $\mathrm{TE}_{22,6}$ Mode Generators ....................................................................... 13

4.3. Gyrotron Distributed Window .......................................................... 13

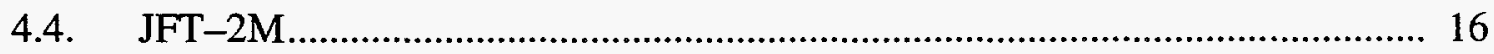

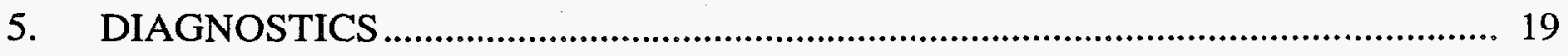




\section{FIGURES}

1. DiMES allows materials to be tested in a tokamak under various operating conditions

2. $\mathrm{TE}_{22,6}$ mode generator, which is used to test the internal launchers in the $\mathrm{MW}$ gyrotron development program

3. The gyrotron distributed window design allows high power microwaves to be transmitted into the plasma without damage to the window

4. This mockup of a combline antenna for JFT-2M will simplify and improve the coupling efficiency and directivity of multi-strap phased arrays for fast wave direct electron heating and fast wave current drive. It will be located between the vessel wall and the surface of the plasma

5. These are the straps that led from conceptual design through analysis to a final design of the magnetic probe for ITER 
Section 1

FUSION TECHNOLOGY DEVELOPMENT OVERVIEW 


\section{FUSION TECHNOLOGY DEVELOPMENT OVERVIEW}

In FY94, the General Atomics (GA) Fusion Group made significant contributions to the technology needs of the controlled fusion power program. The work was supported by the Office of Fusion Energy, Advanced Physics and Technology Division and ITER and Technology Division, of the U.S. Department of Energy. The work is reported in the following sections on Fusion Power Plant Studies (Section 2), Plasma Interactive Materials (Section 3), RF Technology (Section 4), and Diagnostics (Section 5). Meetings attended and publications are listed in their respective sections.

The overall objective of GA's fusion technology research is to develop the technologies necessary for fusion to move successfully from present-day physics experiments to the next-generation fusion reactor experiments, Tokamak Physics Experiment (TPX) and ITER, and ultimately to fusion power plants. To achieve this overall objective, we carry out fusion systems design studies to evaluate the technologies needed for next-step experiments and power reactors, and we conduct research to develop basic knowledge about these technologies, including plasma technologies, fusion nuclear technologies, and fusion materials. We continue to be committed to the development of fusion power and its commercialization by U.S. industry. 
Section 2

FUSION POWER PLANT DESIGN STUDIES 


\section{FUSION POWER PLANT DESIGN STUDIES}

\subsection{OVERVIEW}

The goal of fusion power plant design studies is to provide critical assessment of the projected performance of fusion experiments, reactors, systems and components; to develop potential solutions to critical issues; and to offer recommendations for an improved fusion system. This activity helps to define the goals and $R \& D$ needs of the fusion program, and thus adds focus to near-term activities.

In FY94, GA continued to play a lead role in the Starlite project. Within the Starlite project, we helped to complete the ARIES II, ARIES IV and the PULSAR designs. We contributed in the areas of fusion power core components including plasma facing components, first walls, and blankets and shields. Our work also involved studies of materials, neutronics and safety. We continued to provide senior plasma physics personnel for analysis of disruption effects and for the design of plasma stabilization shells.

\subsection{PROJECT COORDINATION}

For the Starlite/PULSAR study, GA completed the coordination of the ARIES and PULSAR designs, and participated in PULSAR project meetings and conference calls. GA also provided support to the Utility Advisory Committee; the Project Technical Review; the U.S./Japan Fusion Power Plant Design Workshop meetings; and UCLA to administer the IAEA Workshop on Fusion Power Plant Design and Technology,

\subsection{PULSAR DESIGN}

\subsubsection{INTRODUCTION}

A key element in operating the tokamak in a cyclic mode is the design of the energy storage system. This is required by the utility for the uninterrupted supply of electrical power. To address this requirement, the PULSAR engineering team proposed to take advantage of the continuous deposition of thermal energy in the massive outboard shield behind the blanket by using this shield as the thermal storage component of the design. 
We were assigned the task of analyzing this innovative use of the outboard shield for both the helium-cooled and Li-self-cooled blanket options. For the helium-cooled design, a shield configuration based on a SiC-composite nested shell concept was developed. Due to the reduction in neutron fluence, the SiC-composite outboard shield was allowed to operate at a higher temperature than the maximum temperature allowed for either the first wall or blanket. For the Li-self-cooled design, a shield concept based on nested vanadium shells was developed. The vanadium alloy shells contain $1 \mathrm{~cm}$ diameter channels for circulating the coolant. The vanadium shells are separated with a bed of tenelon steel spheres, and are wetted with liquid lithium to enhance thermal conductivity. For both designs, thermal hydraulic estimates demonstrated acceptable energy discharge performance within the material temperature limits of both structural materials. Twodimensional, time-dependent analyses using the finite element TAC2D heat transfer code were utilized. The pumping requirements during the dwell phase of the helium-cooled variant were determined. The cost of additional piping, valves, circulators, etc. required including installation was estimated to be about $\$ 11 \mathrm{M}$ which would have negligible impact on the plant economics. In order to improve the safety rating of the lithium selfcooled design compared to $\mathrm{NaK}$, lithium liquid metal (in which the steel spheres are immersed) was selected as the contacting media. At the conceptual design level, no feasibility issues were identified for either the helium-cooled or Li-self-cooled designs.

\subsubsection{DIVERTOR DESIGN}

Based on simple energy balance modeling similar to that used in the 1994 ITER divertor design, the average and maximum surface heat fluxes were estimated for the PULSAR-I helium-cooled and PULSAR-II lithium-cooled divertor designs. Thermal hydraulic evaluations for different design options were performed. A maximum surface loading of $4.2 \mathrm{MW} / \mathrm{m}^{2}$ can be removed with the $1 \mathrm{~cm}$ diameter cooling tubes and a wall thickness of $1 \mathrm{~mm}$. This means that heat transfer would not be a problem for the lithiumself-cooled, PULSAR-II design assuming successful development of the MHD channel insulating coating. For the helium-cooled SiC/SiC composite PULSAR-I design, internal surface heat transfer enhancement will be needed to remove a maximum surface loading of $3.4 \mathrm{MW} / \mathrm{m}^{2}$. This was based on $0.5 \mathrm{~cm}$ diameter cooling tubes and a tube wall thickness of $1 \mathrm{~mm}$. 


\subsection{STARLITE/DEMO DESIGN PROJECT}

The Starlite/PULSAR design was completed at the midpoint of FY94, and the Starlite team was then reassigned to the Starlite/Demo design.

\subsection{PROJECT PLANNING}

We supported and reviewed the planning and project objectives of the Starlite/Demo Project, and contributed to the mission and design requirements of the Demo design.

\subsection{DEMO DESIGN}

\subsubsection{WORK BREAKDOWN STRUCTURE (WBS)}

We completed the first draft of the Demo Design Work Breakdown Structure (WBS). It was circulated for review and will be used as a vehicle to identify critical design issues.

\subsubsection{CRITICAL DESIGN ISSUES}

We coordinated the initial inputs of critical design issues for different design areas, which include magnet, blanket and divertor designs. The general goals for this task and necessary input format were established. Results of this work will be used for the identification of research and development needs of the Demo design.

\subsubsection{SAFETY AND LICENSING}

Based on a request from DOE/OFE, D. Mears of Gas Cooled Associates (GCA) of San Diego and F. Silady of GA's fission reactor division outlined in detail the necessary steps to get a fusion power plant licensed without going through the fission reactor licensing route, i.e. clean sheet approach.

We also prepared the draft outline of a clean sheet approach on safety and licensing. It consists of four subtasks: 1) define top level regulatory criteria (independent of facility), 2) select licensing basis events, 3) develop regulatory design criteria, and 4) specify regulatory equipment requirements. 


\subsubsection{DIVERTOR DESIGN}

Within the Starlite/Demo project, GA is assigned responsibility for the Plasma Facing Components Design. Work was initiated to develop a comprehensive outline of functional and physical requirements for the Demo divertor design evolving from current devices. The results from this task will form a basis for identifying key elements and prospective deficiencies in $R \& D$ paths leading to Demo.

\subsection{INTERNATIONAL COLLABORATION}

We requested our Russian colleagues from the Kurchatov Institute to work on the helium-cooled Demo divertor design. Different divertor cooling element configurations were evaluated using V-alloy as the structural material. The Russian team developed a robust co-axial tube design that can remove a maximum surface loading of $5 \mathrm{MW} / \mathrm{m}^{2}$. The pumping power required for the design was relatively high but acceptable, while meeting all the material design limits.

\subsection{MEETINGS}

We participated in and contributed papers to the relevant fusion power plant meetings.

\subsection{PUBLICATIONS}

Sager, G.T., et al., "Using the Shield for Thermal Energy Storage in PULSAR," SFNT-3 meeting in Fusion Engineering and Design, June 27-July 1, 1994, Los Angeles, California.

Wong, C.P.C., et al., "Helium-Cooling in Fusion Power Plants," 15th IAEA International Conference on Plasma Physics and Controlled Nuclear Fusion Research, September 26 to October 1, 1994, Seville, Spain 
Section 3

PLASMA INTERACTIVE MATERIALS 


\section{PLASMA INTERACTIVE MATERIALS}

\subsection{INTRODUCTION}

In 1994, we perfected the DiMES sample changer system and began a series of dedicated and piggyback erosion and redeposition experiments. Materials tested included graphite, molybdenum, vanadium and tungsten. The location of DiMES in DIII-D and a closeup view of a sample installed and ready for testing is shown in Fig. 1. We also began safety preparations for the exposure of beryllium coatings in DIII-D, and initiated the preparation of DiMES samples to be exposed to DIII-D disruptions.

\subsection{SAMPLE TRANSFER SYSTEM}

Early in the fiscal year, after a few erosion and redeposition experiments were performed, the DiMES sample changer system was checked out and readied for the next period of plasma operations. Six electrical leads were readied for the Langmuir Probe experiment planned by LLNL. In preparation, we worked on the sample insertion logic and the control panel of the DiMES mechanism. This logic and mechanism simplifies the insertion procedure of the DiMES sample and ensures accurate indication of the sample location. There was a problem with the accumulation of debris on the primary vacuum valve and the design was modified to reduce the occurrence of the problem. Concepts for bringing the fiber optic bundles through the DiMES shaft were also considered for the reflectometer task. This was a concept where we could view the erosion surface thickness change by optical means through fiber optic bundles located at the bottom of the sample. A conceptual design review was held and no significant objections were raised to the technical approach. Further work on this concept is dependent upon additional budget support.

\subsection{DIMES EXPERIMENTS}

The first DiMES program dedicated experiment at DIII-D was performed on October 21, 1993. A DiMES sample (DiMES-8) with implanted 29Si and a coating of tungsten (W) was exposed to six shots of ELM-free H-mode plasma. Discharges for this exposure were developed using two long ELM-free periods (lower single-null) during current flattop to expose DiMES sample to divertor scrape-off-layer fluxes. IR TV and CCD 


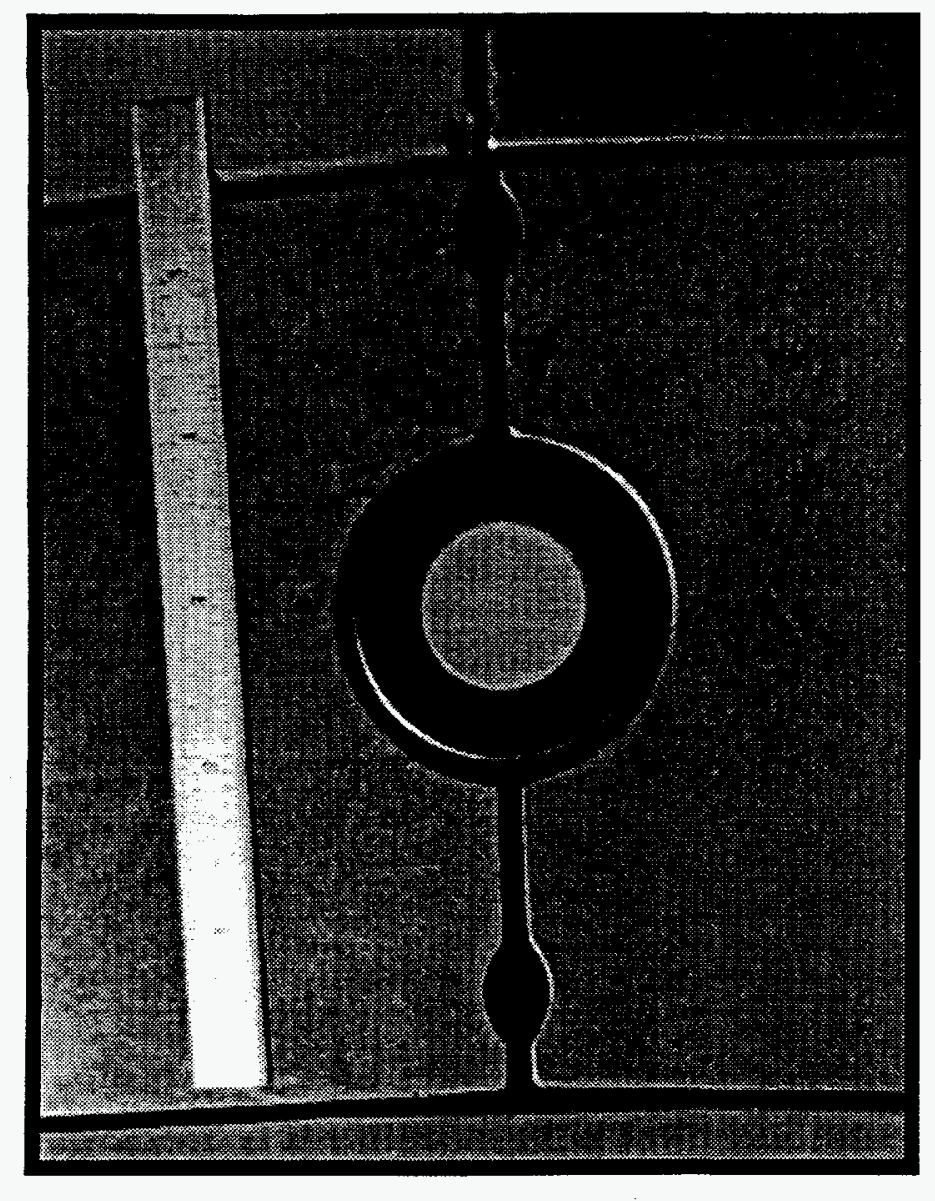

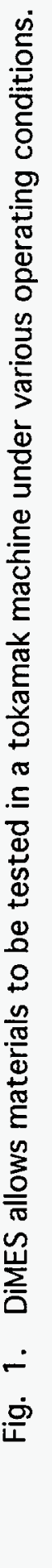
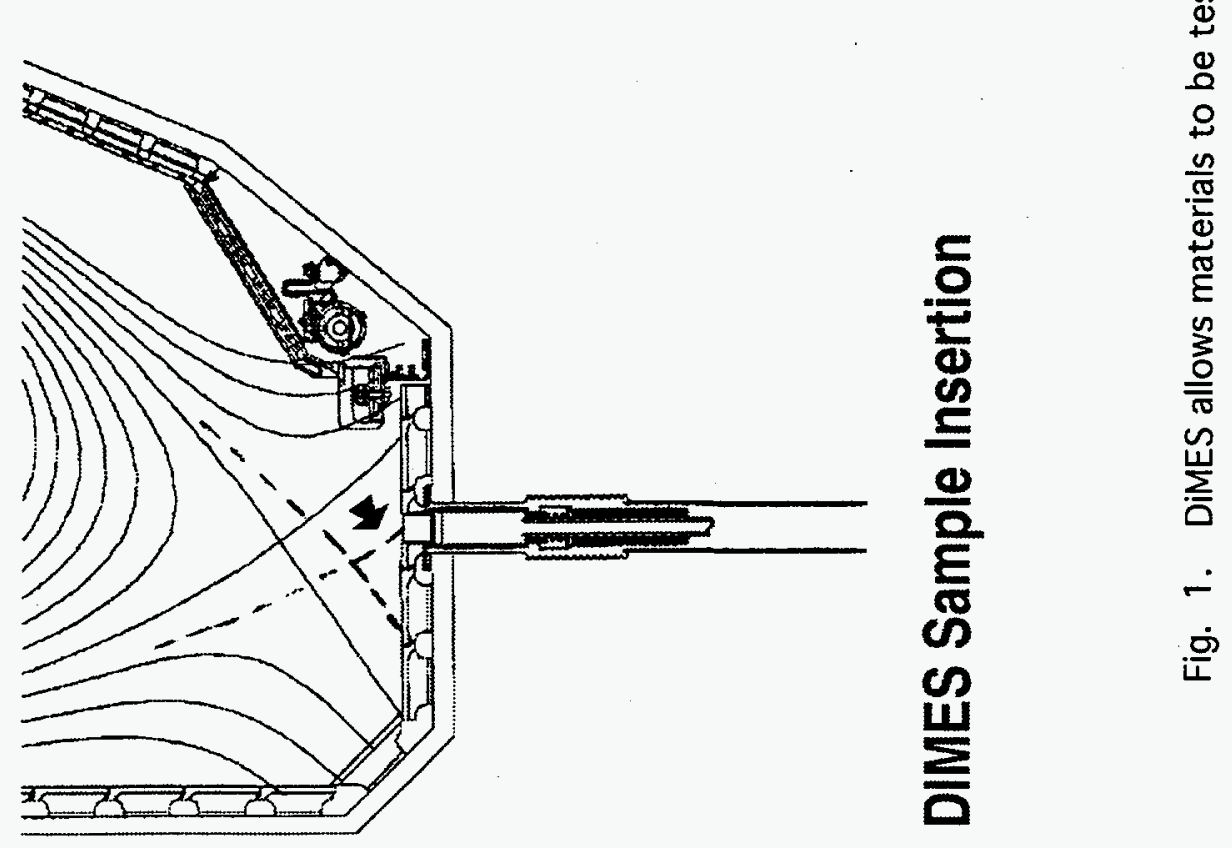
camera data were obtained and analyzed for this exposure. Detailed analysis of this sample was performed in order to understand the temporal evolution of the divertor plasma. Good agreement was obtained by J. Brooks of ANL between code predictions and measured data for the up- and down-field redeposition of tungsten.

A small inward drift in strike point position during the second $\mathrm{H}$-mode phase of each shot was detected when compared to the EFIT data. This shift was found to be visible on the IR camera images as well. Significant carbon erosion was observed, but the tungsten erosion was below the detection limit of $5 \mathrm{~nm}$. However, redistribution of tungsten onto the surrounding carbon was observed. W . Wampler of SNL measured the net erosion of graphite and $\mathrm{W}$ using the Rutherford back scattering technique. In coordination with modeling results we found that the net erosion of graphite is about an order of magnitude lower than gross erosion. Graphite exhibited an erosion rate of about $4 \mathrm{~nm} / \mathrm{s}$ while W exhibited an erosion rate of less than $0.06 \mathrm{~nm} / \mathrm{s}$.

Several samples were exposed in July. On July 11, we recorded deposition onto a bare graphite sample using the colorimetry diagnostic. This technique uses the elaborate color interference patterns on the sample surface. Analysis of these patterns reveals the change in coated material thickness between shots. On July 19, sheath physics was studied with a Sandia sample containing three different Langmuir probe tips. On July 25, a Russian sample with pyrolytic $\mathrm{B}_{4} \mathrm{C}$ coating and an implanted depth marker was exposed. On July 28 , we exposed a graphite sample with an implanted ${ }^{29} \mathrm{Si}$ depth marker to the reference 4-source ELMing $\mathrm{H}$-mode plasma.

\subsection{Be-EXPOSURE}

One of our goals for the erosion and redeposition work is to study the erosion behavior of $\mathrm{Be}$ in a diverted plasma. In order to do that, we must ensure that the exposure of $\mathrm{Be}$ in DIII-D will not cause any safety related (e.g. Be-dust) hazard to DIII-D operating personnel. We reviewed the possibility of exposing a thin $(0.1$ micron $)$ coating of $\mathrm{Be}$ in DIII-D in an erosion experiment. Using plasma conditions similar to the DiMES-8 experiment, the calculated $B e$ erosion rate would be about 0.03 microns/second. We calculated that even after a plasma shot as short as one second, the surface contamination of the DIII-D divertor could exceed the allowable limit of 
$0.24 \mathrm{micro}-\mathrm{gm} / \mathrm{m}^{2}$. We decided to control this potential safety problem by limiting the absolute amount of $\mathrm{Be}$ coated on the sample surface. At the same time we prepared detailed safety procedures for performing this experiment for presentation to the DIII-D safety committee. As practice for the Be-coating exposure experiment, we also decided to practice the safety procedure by using a surrogate sample consisting of $\mathrm{V}$ and Mo coatings.

\subsection{DISRUPTION}

Discussion with the disruption modeling group at ANL indicated that the most useful passive DiMES experiment we can perform is the measurement of the charge exchange neutrals at the target plate prior to the formation of the vapor shield. R. Bastasz of SNL recommended the use of a DiMES sample with a silicon crystal for recording the depth of penetration of the incident neutrals. The preparation of this special sample was implemented.

\subsection{DIAGNOSTICS DEVELOPMENT SUPPORT}

A DiMES probe with three embedded Langmuir probes was also inserted into DIII-D for testing during plasma operations. Although two of the probes failed, one worked successfully, demonstrating the ability to do active instrumentation during DiMES experiments.

\subsection{INTERNATIONAL COLLABORATION}

\subsubsection{GERMANY}

In October of 1993, Dr. Felix Weschenfelder of KFA-Jülich began a one year postdoc assignment at DIII-D. He directed his research efforts from in-situ reflectometry of DiMES samples to ex-situ ellipsometry and in-situ colorimetry. The feasibility of making between-shot color measurements in geometry of the $150 \mathrm{~V}+1$ and $150 \mathrm{R}+2$ ports was demonstrated in laboratory tests using narrow bandpass filters in front of an EEV $\mathrm{B} \& \mathrm{~W}$ CCD camera to detect the interference color pattern from a DIII-D tile illuminated by CER's quartz halogen light source. This technique was demonstrated in an experiment performed on August 1, 1994. 


\subsubsection{PEOPLE'S REPUBLIC OF CHINA}

We completed the first DiMES exchange with Peoples Republic of China (PRC). Professor C. You of the Southwestern Institute of Physics (SWIP) arrived at GA at the beginning of July for a 9 week exchange under the DiMES program. During her stay, she completed the tasks of performing a simple ellipsometer experiment with Dr. F. Weschenfelder, measuring the thickness of boronized coatings, performing sputtering calculations with Dr. P. Parks by using the 1991 version of the TRIM code, and reviewing available literature on material sputtering since 1984. She returned to PRC on August 25, 1994.

\subsection{MEETINGS}

The following papers were presented to the 11th International Conference on Plasma Surface Interactions in Controlled Fusion Devices, May 23-27, 1994, Joyo-Geibun Center, Mitoshi, Ibaraki-ken, Japan.

1. Thanh Q. Hua, et al., "Erosion/Redeposition Anaylis of the DIII-D Divertor."

2. R. Bastasz, et al., "Measurements of Carbon and Tungsten Erosion/Deposition in the DIII-D Divertor." 
Section 4

\section{RF TECHNOLOGY}




\section{RF TECHNOLOGY}

\subsection{COORDINATION OF INTERNATIONAL ACTIVITIES}

The 3rd Bi-annual International ECH Transmission Line workshop was held October 28-29, 1993 at the Inn at Grand Glaize, Osage Beach, Mo. Eighteen scientists and engineers participated, with nineteen technical papers presented.

\subsection{TE22,6 MODE GENERATORS}

Two $\mathrm{TE}_{22,6}$ mode generators for testing the internal launchers for the MW gyrotron development program were fabricated. One mode generator is shown in Fig. 2. One unit was assembled, tested and shipped to the University of Wisconsin in September. This unit had over $98 \%$ mode purity. The second unit was assembled and tested and found to have about $2 \%$ counter rotating mode. This unit was also sent to Wisconsin for further measurements on their far field scanning system. The first unit was sent from the University of Wisconsin to Varian to be used in checking out the mode converter that Varian will put in their new gyrotron tube.

\subsection{GYROTRON DISTRIBUTED WINDOW}

In July the $2 " \mathrm{x} 2$ " prototype distributed window was successfully tested at the JAERI Naka site using their $110 \mathrm{GHz} 500 \mathrm{~kW}$ JAERI/Toshiba Collector Potential Depression gyrotron. The prototype distributed window is shown in Fig. 3. The 2"x2" prototype distributed window was tested in a $32 \mathrm{~mm}$ diameter waveguide system at a power density suitable for a MW gyrotron. A pulse length of 10 times the calculated thermal equilibrium time (1/e time) of $30 \mathrm{msec}$ was reached, and the window passed at least 750 pulses greater than $30 \mathrm{msec}$ and 343 pulses greater than $60 \mathrm{msec}$.

Beyond $100 \mathrm{msec}$, the window calorimetry reached steady state, allowing the window heat dissipation to be measured in a single pulse. The measured loss of $4.0 \%$ agrees both with the estimated loss on which our stress calculations are based, and with the attenuation measured at low power in the $\mathrm{HE}_{11}$ mode. After the end of the tests, the window was examined. No evidence of arcing or coating was found in the part of the window directly illuminated by the microwaves, although there was discoloration in a 


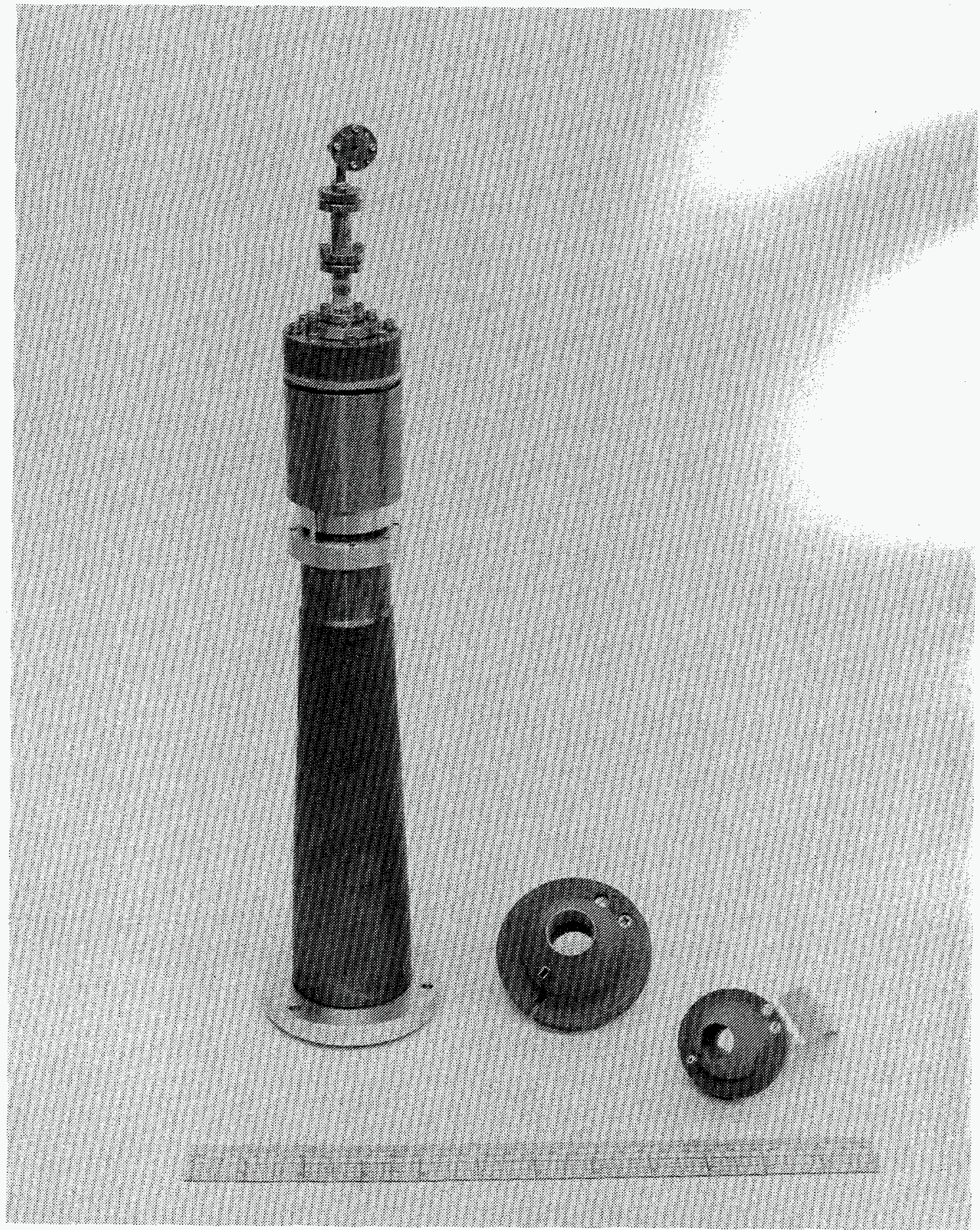

Fig. 2. $A \mathrm{TE}_{22,6}$ mode generator, which is used to test the internal launchers in the $\mathrm{MW}$ gyrotron development program. 


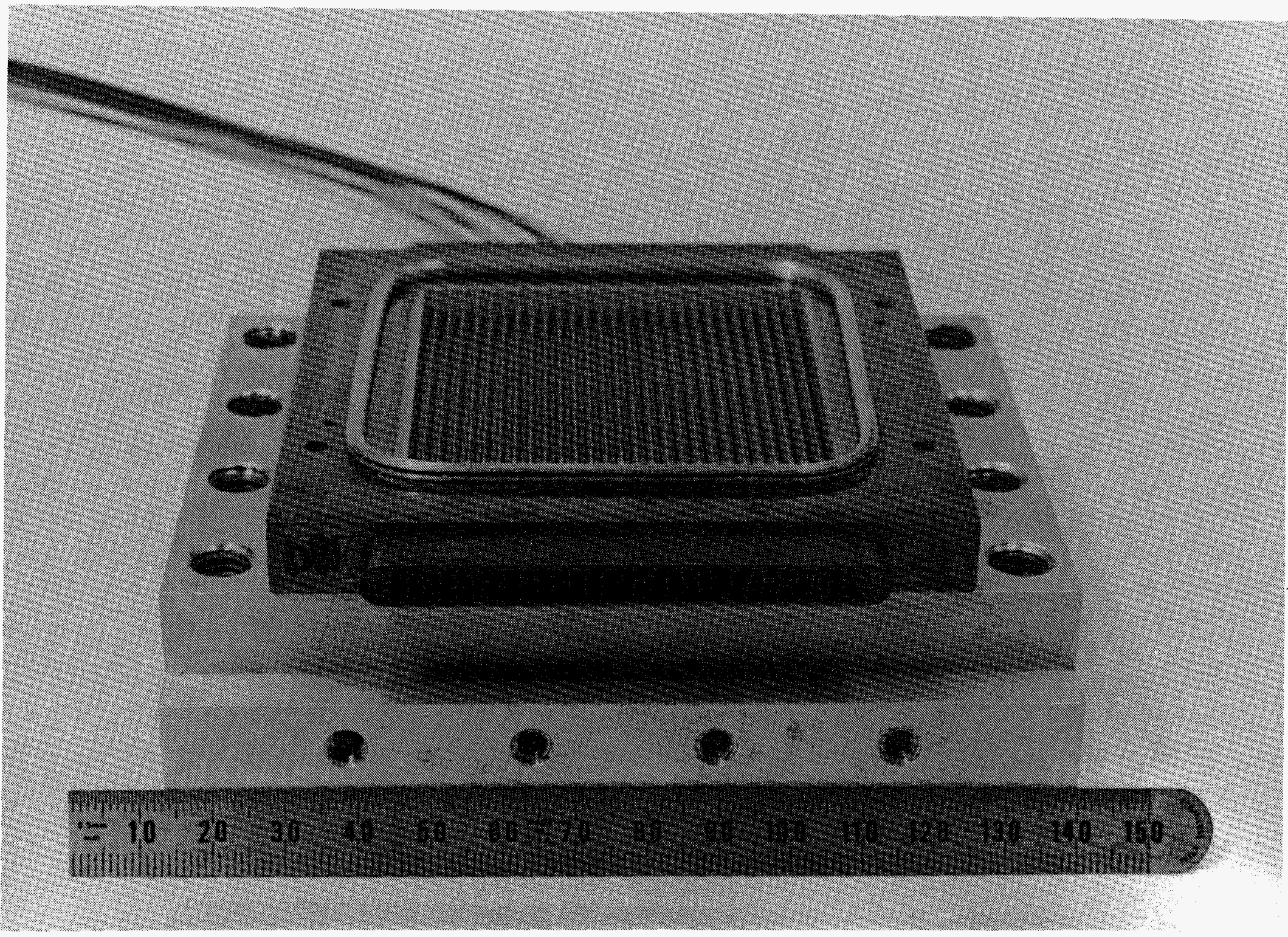

Fig. 3. The gyrotron distributed window design allows high power microwaves to be transmitted into the plasma without damage to the window. 
recess containing an optical diagnostic which outgassed, causing a local discharge to occur in that recess.

To summarize, a peak power of $30 \mathrm{~kW} / \mathrm{cm}^{2}$ was passed through the distributed window for pulses as long as $300 \mathrm{msec}, 343$ pulses longer than $60 \mathrm{msec}, 750$ pulses longer than $30 \mathrm{msec}$, and an accumulated "on time" of $50 \mathrm{sec}$. The $30 \mathrm{~kW} / \mathrm{cm}^{2}$ is consistent with $1 \mathrm{MW}$ in a $10 \mathrm{~cm}$ diameter window with a slightly flattened profile. In addition several pulses were completed at a power level of $40 \mathrm{~kW} / \mathrm{cm}^{2}$ with an accumulated "on time" of $7.5 \mathrm{sec}$. The level of $40 \mathrm{~kW} / \mathrm{cm}^{2}$ is consistent with $1 \mathrm{MW}$ $10 \mathrm{~cm}$ diameter circular $\mathrm{HE}_{11}$ mode.

While flushing the water channels with water preparatory to etching the 2" 8 " window, a leak was discovered between a water channel and the microwave region of the window. The flaw is visible in bright light, and is clearly the result of a pilot hole which was mis-located and wandered from perpendicular. Upon inspection at least five other cooling channels were found to have thin walls caused by misguided pilot holes.

This large number of questionable cooling channels led to the decision to rebuild the window frame rather than repair the existing unit. Since the gyrotron development program has changed direction away from a rectangular window it was decided to build a square $4 " \mathrm{x} 4$ " inch window as the next distributed window which can easily replace the present circular window. GA is working with the cooling channel manufacturer to improve the quality of their product. Extra inspection steps have been added and process prototyping is now in progress. The sapphire and the niobium plate for the new window have been ordered.

\subsection{JFT-2M COMBLINE ANTENNA}

Discussions were held with members of the JFT-2M team and it does not look like two adjacent ports will be available next year to mount a multi-strap combline owing to the large effort it would take to remove the items from the wall between the two ICRF ports. This leaves only one port available to mount a combline antenna and we are in the process of reviewing the effect this would have on achieving a successful demonstration of the combline antenna concept. A mockup of the combline antenna for JFT-2M is shown in Fig. 4. 


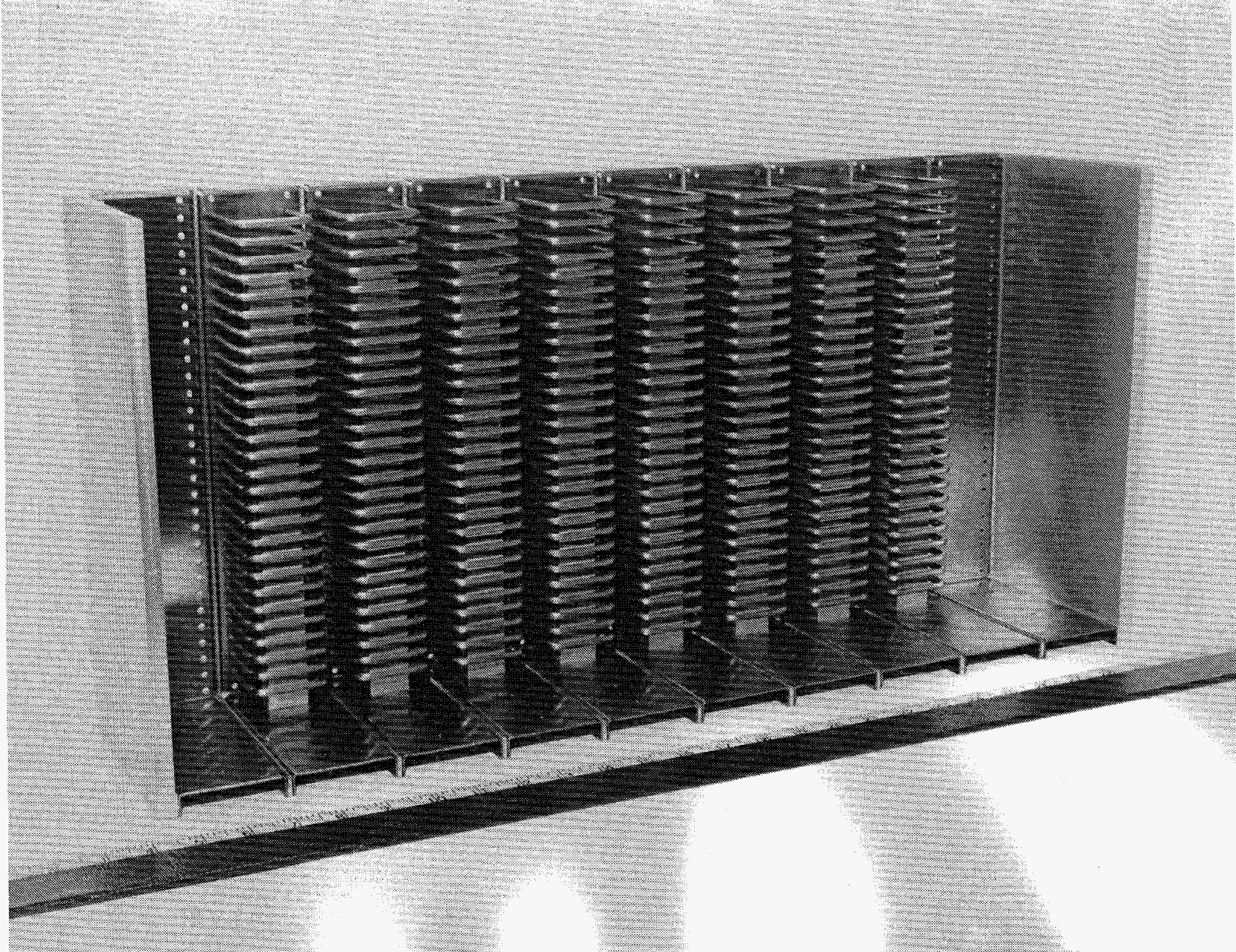

Fig. 4. This mockup of a combline antenna for JFT-2M will simplify and improve the coupling efficiency and directivity of multi-strap phased arrays for fast wave direct electron heating and fast wave current drive. It will be located between the gap between the vessel wall and the surface of the plasma. 
Section 5

DIAGNOSTICS 


\section{DIAGNOSTICS}

Work on the development of radiation-resistant magnetic probes for ITER was authorized on August 15, 1994. In the remaining 7 weeks of CY94, the design of the test magnetic coils was started and a preliminary design of the coils was completed. The design of the long pulse integrators was started and procurement of data acquisition equipment for the long pulse integrators was initiated.

Details of the test module to be inserted into the Brookhaven reactor were discussed with Lance Snead of ORNL during his visit to GA. GA also will be acting as a consultant to ORNL on specifications of mineral insulated (MI) cable. The steps leading from a conceptual design through analysis to the final design of the magnetic probe for ITER are shown in Fig. 5. 
STEP 1 - Magnetic Probe Conceptual Design

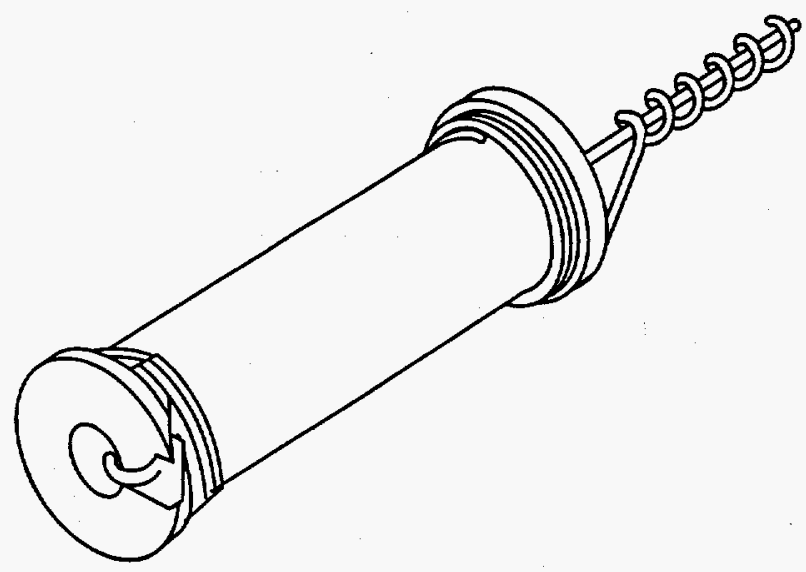

STEP 3 - Axisymmetric FEA Model of Magnetic Probe

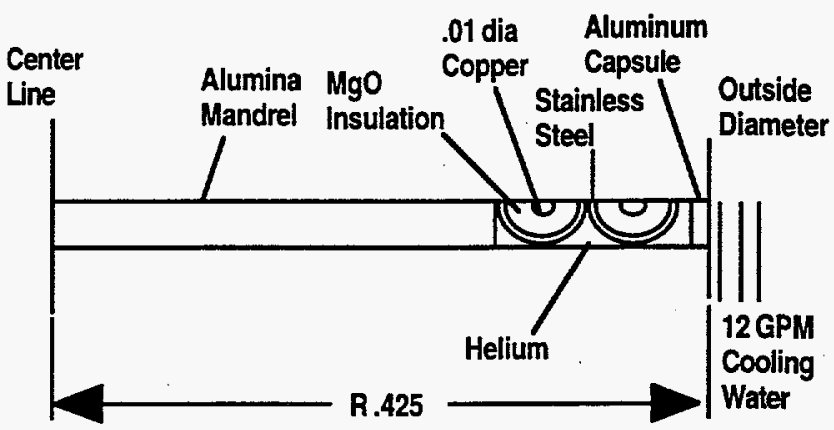

STEP 2 - Graph Showing Surface Temperature of Capsule Will Not Cause Cooling Water to Boil

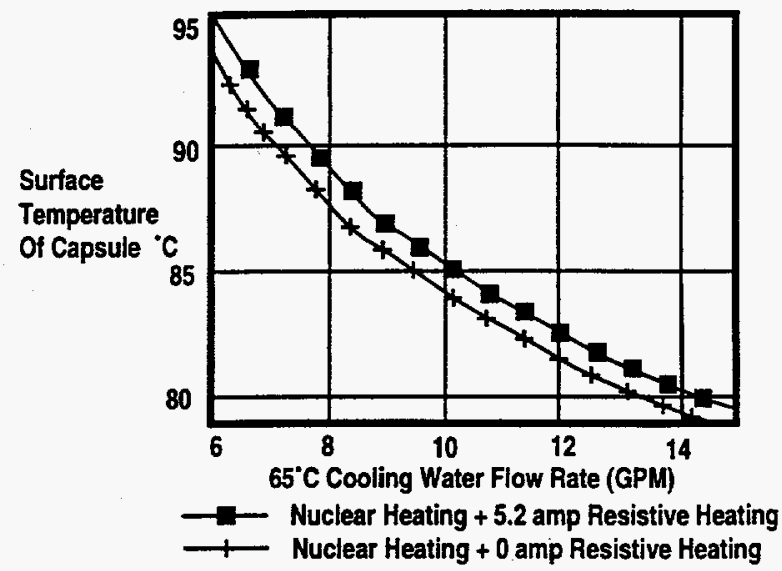

STEP 4 - Temperature Inside Magnetic Probe vs. Radius Calculated Using COSMOS FEA Code

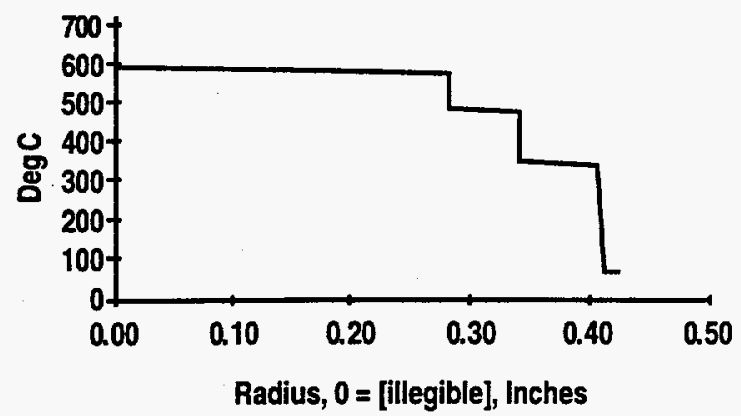

STEP 5 - Final Design of ITER Magnetic Probe

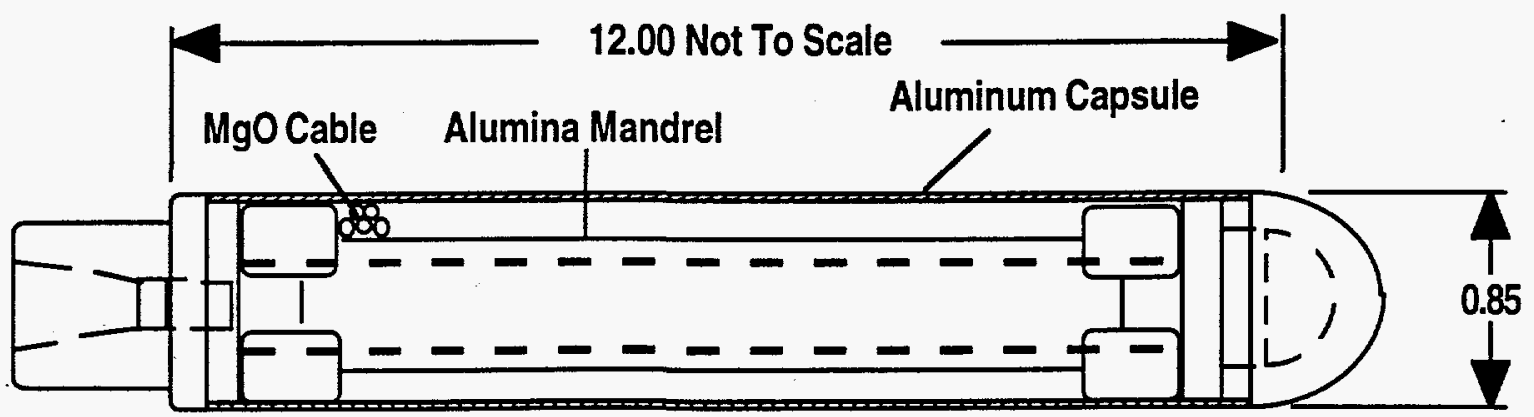

Fig. 5. These are the steps that led from conceptual design through analysis to a final design of the magnetic probe for ITER. 